\title{
Analysis on the Tactics and Benefit of Vertical Cooperative R\&D Innova- tion in Supply Chain
}

\author{
Sheng Xiaojuan ${ }^{1, *}$, Wang $Z_{\text {he }}^{2}$ and Xue Wanxin ${ }^{1}$ \\ ${ }^{1}$ School of Management, Beijing Union University, Beijing, 100101, P.R. China; ${ }^{2}$ Dongling School of Economics and \\ Management, University of Science and Technology Beijing, Beijing, 100070, P.R. China
}

\begin{abstract}
Vertical cooperative innovation during supply chain may overcome the high investment in R\&D and uncertainty, and it also can avoid risks, shorten product development cycles. In this paper, a vertical cooperative R\&D model is built in the upstream monopoly supply chain based on game theory. The following conclusions is drawn: Monopoly in the upstream vertical cooperative R\&D model, with the absorptive capacity of enterprises and the overflow level of the increase in corporate $R \& D$ results, the upstream and downstream businesses will increase profits. The upstream monopoly enterprise cannot force the downstream companies to join the cooperative R\&D alliance, and undertake research and development costs too much. To maximize profits, the upstream companies can only travel companies in the following bound for the standard to determine the number of member companies and the downstream cost-sharing ratio.
\end{abstract}

Keywords: Complete monopoly, cooperative innovation, game theory, supply chain, vertical cooperation.

\section{INTRODUCTION}

With the increasingly fierce market competition, enterprises realize that they can only survive by continuous innovation. The enterprises shall realize product innovation by relying on technical innovation so as to satisfy the changing demands of the consumers. However, since the resources, capacity and knowledge system possessed by an enterprise are limited, it is very difficult to obtain innovative advantages by relying one's own strength. Therefore, cooperation becomes especially important. The implementation of cooperative $R \& D$ can realize complementing of advantages of each partner and enable them to jointly complete technical innovation and product innovation as well as share the benefits. In the recent decades, cooperative R\&D model has been very commonly executed in the enterprises [1].

In many industries especially manufacturing industry, the cooperative R\&D innovation among upstream and downstream enterprises with business contact is relatively frequent. R\&D activities of upstream (downstream) enterprise will reinforce the competitiveness of downstream (upstream) enterprises and increase their profits. This kind of $R \& D$ cooperation is usually called as "vertical cooperative $R \& D$ model". Compared with horizontal cooperative R\&D, people has done fewer researches on vertical cooperation [2]. However, the cases of vertical cooperation in the production practice are considerable. With the proposal of the concept of value chain, people become increasingly aware of vertical cooperation as an effective approach to improve the overall value of the supply chain. As a matter of fact, due to consistent competitive relation, great barriers and disagreements exist during the cooperation of horizontal enterprises, including corporate culture, moral risk, trust risk, etc. However, there are no obvious competition and conflict of interest existing among upstream and downstream enterprises of the supply chain. They usually have a dependency relationship and thus it is very easy for them to reach a united front.

Among literatures studying vertical cooperative innovation, two articles by Samiran Banerjee and Akira Ishii have established a basic theoretic analysis framework for the researches of the successor. Samiran Banerjee put forward a vertical RJV model for the first time. This model has studied the tactics that an upstream monopoly enterprise joins with $n$ downstream enterprises to form RJV model in a secondary supply chain system with upstream enterprise as the independent monopoly enterprise as well as discussed the influence of different cost sharing methods on RJV scale and total profit. Besides, Samiran Banerjee still took the abovementioned vertical industry system as the study object and assumed that $\mathrm{n}$ downstream enterprises form RJV to conduct cooperative $R \& D$ at this point, while the upstream enterprise is able to select the best selling prices according to the product demands of the downstream enterprises. Also, the influence of fixed price model and floating pricing model adopted by the upstream enterprise on the cooperative R\&D tactics of the downstream enterprises as well as how the downstream RJV member enterprises prevent the speculative behaviors of upstream enterprise have been studied. Akira Ishii [3] has constructed a vertical industry system composed of two upstream enterprises and two downstream enterprises and assumed that horizontal and vertical technology overflow effects exist in this system. Then, a vertical duopoly cooperative R\&D model has been established, and the influence of vertical RJV on technical R\&D has been studied. The research indicated that vertical R\&D cartel can bring more social benefits compared with non-cooperative R\&D behav- 
iors under the condition that the overflow level between supply chains is relatively low. Besides, when vertical enterprises can coordinate with R\&D actions or share useful information, vertical RJV cartel can obtain the maximum social benefits [4]. However, this model has only discussed the cooperative R\&D tactics of vertical RJV under the condition of output competition but failed to consider the cooperative $R \& D$ tactics under the condition of price competition.

In the research of this paper, three-stage game idea is adopted to launch the study of vertical cooperative $R \& D$ innovation tactics and benefit with complete upstream monopoly. Due to information asymmetry and different market positions, cooperative innovation participants launch Stackelberg price competition to finally reach a balanced status. Meanwhile, the paper analyzes and concludes the cooperative attitude of each enterprise and the best alliance scale by comparing the indexes of various R\&D statuses like profit, output and R\&D effect.

\section{PROBLEM DESCRIPTION}

When implementing technical R\&D, the upstream enterprise leading in the secondary supply chain requires the downstream enterprises to provide relevant technologies or products. Besides, the benefits brought by the R\&D results of the upstream enterprise will spill to the downstream enterprises through the sales of intermediate products to benefit the downstream enterprises. Therefore, when conducting technical R\&D, the upstream enterprise may unite with some downstream enterprises to form a cooperative $R \& D$ alliance and make the downstream member enterprises to obtain certain R\&D profit or market competitive advantages and undertake some R\&D costs [5]. In literature, Samiran Banerjee assumes that the R\&D investment of the upstream enterprise is $\mathrm{F}$ in a secondary supply chain composed of one upstream enterprise and $\mathrm{N}$ downstream enterprise and the production cost is reduced from $\mathrm{c} 1$ to $\mathrm{c} 2$. In other words, it has mainly studied the influence of cost-sharing tactics adopted by the upstream enterprise like profit ratio or fixed ratio on the scale of the downstream member enterprises given $R \& D$ investment and effect. However, this paper fixes the R\&D investment and effect and fails to discuss if the cooperation will of the downstream enterprises would influence the cooperative tactics of the upstream enterprise or reveal the trends of R\&D effect and investment with the change of quantity of downstream member enterprises.

Besides, the analysis of economists on the R\&D alliance is based on the technology overflow effect. Some empirical researches indicate that overflow effect does not only exist in the industry but also among industry supply chains. For a long time, the analysis of overflow effect existing among supply chains has often been ignored. Although some researches point out that vertical $\mathrm{R} \& \mathrm{D}$ alliance can internalize the technology overflow effect and motivate the R\&D investment, the researches on form selection of vertical $R \& D$ alliance are still rare [6].

Therefore, this paper has established a secondary supply chain structure with complete upstream monopoly. Meanwhile, in consideration of the absorptive capacity and overflow effect of the enterprises, it has internalized the cost- sharing ratio, $R \& D$ effect and $R \& D$ input of the upstream enterprise and discussed the influence of the cooperative $R \& D$ tactics of the upstream enterprise on the scale of cooperation alliance, cost-sharing ratio, $R \& D$ effect and profits of upstream and downstream enterprises when the upstream enterprise conducts technical R\&D [7].

In a secondary supply chain system with complete upstream monopoly, there is one upstream enterprise and $\mathrm{N}$ downstream enterprises. When no cooperative $R \& D$ is carried out, the production cost and transfer price of intermediate product of the upstream enterprise are $c_{0}$ and $p_{0}$ respectively; the downstream enterprises manufacture the intermediate product to homogeneous final product according to one-to-one ratio and the competition of market where the downstream enterprises are located will finally reach Cournot equilibrium. Set the reverse demand function of downstream enterprises as $P=a-Q$, and then the total output of the downstream enterprises is $Q=\sum_{i=1}^{N} q_{i}$. Now, the upstream enterprise starts to conduct technical innovation to low the production cost by $\theta$. The upstream enterprise can select independent or cooperative $R \& D$. If the upstream enterprise adopts independent R\&D tactic, it will have to undertake cooperative $R \& D$ cost and provide intermediate product for downstream enterprises with a new price $p_{s}$. If the upstream enterprise adopts cooperative $R \& D$ tactic, it plans to invite $n(0 \leq n \leq N)$ downstream enterprises to form a cooperative $R \& D$ alliance to share the $R \& D$ cost. The $R \& D$ cost ratio undertaken by the upstream enterprise is $S$, and the downstream member enterprises jointly undertake the remaining $(1-S)$. Besides, the upstream enterprise provides intermediate product or downstream member enterprises at the price of $p_{c}$, and provides intermediate product for downstream non-member enterprise at the original price of $p_{0}$.

It is assumed here that $p_{0}, p_{s}, p_{c}$ represent transfer price of intermediate price before $R \& D$, during independent $R \& D$ and during cooperative $\mathrm{R} \& \mathrm{D}$ respectively; $q_{d i}^{0}, q_{d i}^{s}, q_{d i}^{c}$ represent the outputs of downstream enterprises before $R \& D$, during independent $\mathrm{R} \& \mathrm{D}$ and during cooperative $\mathrm{R} \& \mathrm{D}$ respectively; $Q_{d}^{0}, Q_{d}^{s}, Q_{d}^{c}$ represent the total output of downstream enterprises before $R \& D$, during independent $R \& D$ and during cooperative $\mathrm{R} \& \mathrm{D}$ respectively; $\pi_{d i}^{0}, \pi_{d i}^{s}, \pi_{d i}^{c}$ represent the profit of downstream enterprises before $R \& D$, during independent $R \& D$ and during cooperative $R \& D$ respectively; $\pi_{d i}^{c}, \pi_{d j}^{c}$ represent profit of upstream member enterprises and profit of upstream non-member enterprises during cooperative R\&D respectively; $\pi_{u}^{0}, \pi_{u}^{s}, \pi_{u}^{c}$ represent the profit of upstream enterprise before $R \& D$, during independent $\mathrm{R} \& \mathrm{D}$ and during cooperative $\mathrm{R} \& \mathrm{D}$ respectively; $\theta_{s}, \theta_{c}$ represent $R \& D$ benefit during independent $R \& D$ and during cooperative R\&D respectively; $\omega$ represents other production cost of downstream enterprise beside the payment of price of intermediate product; $\gamma$ represents coefficient of 
difficulty of $\mathrm{R} \& \mathrm{D} ; \quad \beta$ represents technology (information) overflow coefficient; $k$ represents absorptive capacity.

\section{MODELING}

\subsection{Initial Status before R\&D}

In order to seize the market share, the downstream manufacturers are engaged in a game about output to finally reach count equilibrium [8]. Then, the profit function of each single downstream enterprise is as follows:

$$
\pi_{d i}^{0}=\left[a-\sum_{i=1}^{N} q_{d i}^{0}-\left(p_{0}+\omega\right)\right] q_{d i}^{0}
$$

Solve the output related to profit maximization, i.e. $\frac{\partial \pi_{d i}^{o}}{\partial q_{d i}^{0}}=0$. Then the following can be solved.

$$
\begin{aligned}
& q_{d i}^{0}=\frac{a-\left(p_{0}+\omega\right)}{N+1} \\
& Q_{d}^{0}=N q_{d i}^{0}=\frac{N\left(a-p_{0}-\omega\right)}{N+1}
\end{aligned}
$$

The profit function of upstream enterprise is:

$\pi_{u}^{0}=\left(p_{0}-c_{0}\right) Q_{d}^{0}=\left(p_{0}-c_{0}\right) \frac{N\left(a-p_{0}-\omega\right)}{N+1}$

Carry out first deviation of $p_{0}$ in formula (1) and make $\frac{\partial \pi_{u}^{0}}{\partial p_{0}}=0$ to obtain:

$$
p_{0}=\frac{a+c_{0}-\omega}{2}
$$

Therefore, the profit function of the upstream enterprise is as follows:

$\pi_{u}^{0}=\frac{N\left(a-c_{0}-\omega\right)^{2}}{4(N+1)}$

The profit function of the downstream enterprises is as follows:

$\pi_{d i}^{0}=\frac{\left(a-c_{0}-\omega\right)^{2}}{4(N+1)^{2}}$

The function of output of single downstream enterprise and the total output is as follows:

$$
\left\{\begin{array}{l}
q_{d i}^{0}=\frac{a-c_{0}-\omega}{2(N+1)} \\
Q=\frac{N\left(a-c_{0}-\omega\right)}{2(N+1)}
\end{array}\right.
$$

\subsection{Independent $R \& D$ Innovation}

When the upstream enterprise conducts independent R\&D innovation, the production cost of the product declines from $c_{0}$ to $c_{0}-\theta_{s}$. The $\mathrm{R} \& \mathrm{D}$ cost is $\frac{1}{2} \gamma \theta_{s}^{2}$. At this point, the transfer price of intermediate product changes from $p_{0}$ to $p_{s}$. Then, the unit product cost of the downstream enterprises is $\left(p_{s}+\omega\right)$. Therefore, the profit function of the downstream enterprises is as follows:

$$
\pi_{d i}^{s}=\left[a-\sum_{i=1}^{N} q_{d i}^{s}-\left(p_{s}+\omega\right)\right] q_{d i}^{s}
$$

Carry out first deviation and make $\frac{\partial \pi_{d i}^{s}}{\partial q_{d i}^{s}}=0$ to obtain:

$$
\begin{aligned}
q_{d i}^{s} & =\frac{a-\left(p_{s}+\omega\right)}{N+1} \\
Q^{s} & =\frac{N\left(a-p_{s}-\omega\right)}{N+1}
\end{aligned}
$$

During independent R\&D innovation, the profit function of the upstream enterprise is as follows:

$$
\begin{aligned}
& \pi_{u}^{s}=\left(p_{s}-c_{0}+\theta_{s}\right) Q^{s}-\frac{1}{2} \gamma \theta_{s}^{2} \\
& \ldots .=\frac{N\left(a-p_{s}-\omega\right)\left(p_{s}-c_{0}+\theta_{s}\right)}{N+1}-\frac{1}{2} \gamma \theta_{s}^{2}
\end{aligned}
$$

Carry out first deviation of $p_{s}$ in formula (5) and make $\frac{\partial \pi_{u}^{s}}{\partial p_{s}}=0$ to obtain:

$$
p_{s}=\frac{a+c_{0}-\omega-\theta_{s}}{2}
$$

Substitute the value of $p_{s}$ to the upstream and downstream profit functions to obtain the following functions:

$$
\left\{\begin{array}{l}
\pi_{u}^{s}=\frac{N\left(a-c_{0}-\omega+\theta_{s}\right)^{2}}{N+1}-\frac{1}{2} \gamma \theta_{s}^{2} \\
\pi_{d i}^{s}=\frac{\left(a-c_{0}-\omega+\theta_{s}\right)^{2}}{4(N+1)^{2}}
\end{array}\right.
$$

Substitute the value of $p_{s}$ to the output function to obtain the output of single enterprise and total output:

$$
\left\{\begin{array}{l}
q_{d i}^{s}=\frac{a-c_{0}+\theta_{s}-2 \omega}{2(N+1)} \\
Q^{s}=\frac{N\left(a-c_{0}+\theta_{s}-2 \omega\right)}{2(N+1)}
\end{array}\right.
$$

Solve first derivative of the $R \& D$ effect from the profit function of the upstream enterprise. In other words, make $\frac{\partial \pi_{u}^{s}}{\partial \theta_{s}}=0$.

The optimum condition can be used to solve and obtain: $\theta_{s}^{*}=\frac{N\left(a-c_{0}-\omega\right)}{2(N+1)-N}$ 
Substitute the value of $\theta_{s}$ to the upstream profit function to obtain:

$$
\pi_{u}^{s}=\frac{N\left(a-c_{0}-\omega\right)^{2}}{4(N+1)-N / \gamma}
$$

\subsection{Cooperative $R \& D$ Innovation}

If the upstream enterprise conducts cooperative R\&D innovation with $\mathrm{n}(n \leq N)$ downstream enterprises, the production cost $c_{0}$ declines to $\left(c_{0}-\theta_{c}\right)$. The $\mathrm{R} \& \mathrm{D}$ cost is $\frac{1}{2} \gamma \theta_{c}^{2}$. The R\&D cost ratio shared by the downstream member enterprises is $(1-S)$. Then, the cooperative $\mathrm{R} \& \mathrm{D}$ cost ratio that shall be shared by single member enterprise becomes $(1-S) / n$. As for downstream member enterprises participating in $\mathrm{R} \& \mathrm{D}$, the transfer prices of the intermediate product changes from $p_{0}$ to $p_{c}$, while the transfer price of intermediate product of non-member enterprises is still $p_{0}$. Vertical technology overflow exists between upstream and downstream enterprises participating in cooperation [9]. At this point, the profit functions of downstream member enterprises and downstream non-member enterprises are as follows respectively:

$$
\begin{aligned}
& \pi_{d i}^{c}= {\left[a-\sum_{i=1}^{n} q_{d i}^{c}-\sum_{j=n+1}^{N} q_{d j}^{c}-\left(p_{c}+\omega-k \beta \theta_{c}\right)\right] q_{d i}^{c}-\frac{1-S}{2 n} \gamma \theta_{c}^{2} } \\
& i=1,2,3 \ldots n \\
& \pi_{d j}^{c}= {\left[a-\sum_{i=1}^{n} q_{d i}^{c}-\sum_{j=n+1}^{N} q_{d j}^{c}-\left(p_{0}+\omega\right)\right] q_{d j}^{c} } \\
& j=n+1, n+2, \ldots . . N
\end{aligned}
$$
tion:

The following formula can be obtained from first deriva-

$$
\left\{\begin{array}{l}
q_{d i}^{c}=\frac{\left(a-\omega+k \beta \theta_{c}\right)-(N-n+1) p_{c}+(N-n) p_{0}}{N+1} \\
q_{d j}^{c}=\frac{(a-\omega)-(n+1) p_{0}+n p_{c}}{N+1}
\end{array}\right.
$$

The profit function of the upstream enterprise is:

$$
\begin{aligned}
\pi_{u}^{c}= & {\left[p_{c}-c_{0}+(1+k \beta) \theta_{c}\right] n q_{d i}^{c} } \\
& +\left[p_{0}-c_{0}+(1+k \beta) \theta_{c}\right](N-n) q_{d j}^{c}-\frac{S}{2} \gamma \theta_{c}{ }^{2}
\end{aligned}
$$

Carry out first derivation to obtain:

$$
p_{c}=\frac{a-\omega+c_{0}+(k \beta-1) \theta_{c}+(N-n) p_{0}}{N-n+2}
$$

Substitute $p_{0}=\frac{a+c_{0}-\omega}{2}$ to the formula above to obtain:

$$
p_{c}=\frac{a+c_{0}-\omega}{2}-\frac{(2-k \beta) \theta_{c}}{N-n+2}
$$

Then, the profits of the upstream enterprise, downstream member enterprise, and downstream non-member enterprise are obtained respectively:

$$
\left\{\begin{aligned}
\pi_{u}^{c}= & \frac{n}{N+1}\left(\frac{a-c_{0}-\omega}{2}+\frac{(N-n+1)(1+k \beta)}{N-n+2} \theta_{c}\right)^{2} \\
& +\frac{N-n}{N+1}\left(\frac{a-c_{0}-\omega}{2}-\frac{n(2-k \beta) \theta_{c}}{N-n+2}\right)\left(\frac{a-c_{0}-\omega}{2}+\theta_{c}\right)-\frac{S}{2} \gamma \theta_{c}^{2} \\
\pi_{d i}^{c}= & \frac{1}{(N+1)^{2}}\left(\frac{a-c_{0}-\omega}{2}+\frac{(N-n+1)(1+k \beta)}{N-n+2} \theta_{c}\right)^{2}-\frac{1-S}{2} \gamma \theta_{c}^{2} \\
\pi_{d j}^{c}= & \frac{1}{(N+1)^{2}}\left(\frac{a-c_{0}-\omega}{2}-\frac{n \theta_{c}}{N-n+2}\right)^{2}
\end{aligned}\right.
$$

Make $\frac{\partial \pi_{u}^{s}}{\partial \theta_{c}}=0$ to obtain:

$$
\theta_{c}=\frac{N\left(a-c_{0}-\omega\right)}{2(N+1)(2-k \beta)} \frac{1+k \beta}{\gamma S-\frac{2 n}{(N+1)(N-n+2)^{2}}}
$$

Therefore, the profit of the upstream enterprise is as follows:

$$
\begin{aligned}
\pi_{u}^{c}= & \frac{N\left(a-c_{0}-\omega\right)^{2}}{4(N+1)(2-k \beta)} \\
& +\frac{N^{2}\left(a-c_{0}-\omega\right)^{2}}{8(N+1)^{2}(2-k \beta)^{2}} \frac{1+k \beta}{\gamma S-\frac{2 n}{(N+1)(N-n+2)^{2}}}
\end{aligned}
$$

\section{MODEL ANALYSES}

\subsection{Comparative Analysis of Initial Status and Inde- pendent $R \& D$}

In order to facilitate comparative analysis, various indexes during initial status and independent R\&D are summarized in Table 1.

(1) When the upstream enterprise conducts independent R\&D innovation, the transfer price of intermediate product is lower than that of intermediate product in the initial status.

Formula $p_{s}-p_{0}=-\frac{\theta_{s}^{*}}{2}<0$ indicates that the upstream enterprise has realized technical innovation and lowered product cost so as to lower the transfer price of its intermediate product when conducting independent $R \& D$.

(2) During independent R\&D innovation, the profits and total output of the upstream and downstream enterprises are greater than those in the initial status.

$\left\{\begin{array}{l}\pi_{u}^{s} / \pi_{u}^{0}=\frac{4(N+1)}{4(N+1)-N / \gamma}>1 \\ \pi_{d i}^{s} / \pi_{d i}^{0}=\frac{\left(a-c_{0}-\omega+\theta_{s}^{*}\right)^{2}}{\left(a-c_{0}-\omega\right)^{2}}>1 \\ Q^{s}-Q^{0}=\frac{\theta_{s}^{*}-\omega}{2(N+1)}>0\end{array}\right.$

Therefore, the statement above is established. 
Table 1. Profit function and benefit function of upstream and downstream enterprises under each R\&D status.

\begin{tabular}{|c|c|c|}
\hline & Initial Status & Independent R\&D \\
\hline \hline Price of intermediate product & $p_{0}=\frac{a+c_{0}-\omega}{2}$ & $p_{s}^{*}=\frac{a+c_{0}-\omega-\theta_{s}^{*}}{2}$ \\
\hline Profit of upstream enterprise & $\pi_{u}^{0}=\frac{N\left(a-c_{0}-\omega\right)^{2}}{4(N+1)}$ & $\pi_{u}^{s}=\frac{N\left(a-c_{0}-\omega\right)^{2}}{4(N+1)-N / \gamma}$ \\
\hline Profit of downstream enterprise & $\pi_{d i}^{0}=\frac{\left(a-c_{0}-\omega\right)^{2}}{4(N+1)^{2}}$ & $\pi_{d i}^{s}=\frac{\left(a-c_{0}-\omega+\theta_{s}^{*}\right)^{2}}{4(N+1)^{2}}$ \\
\hline Total output & $Q^{0}=\frac{N\left(a-c_{0}-\omega\right)}{2(N+1)}$ & $Q^{s}=\frac{N\left(a-c_{0}+\theta_{s}^{*}-2 \omega\right)}{2(N+1)}$ \\
\hline R\&D benefit function & & $\theta_{s}^{*}=\frac{N\left(a-c_{0}-\omega\right)}{2(N+1)-N}$ \\
\hline
\end{tabular}

\subsection{Analysis of Cooperative R\&D Innovation Model}

(1) When the enterprise conducts cooperative R\&D innovation, the R\&D effect of the enterprise increases with the increase of absorptive capacity and overflow level of the enterprise; the profits of upstream enterprise and downstream member enterprises also increase with the increase of absorptive capacity and overflow level of the enterprise.

We can see from formula (7) that:

$$
\left\{\begin{array}{l}
\frac{\partial \theta_{c}}{\partial k}>0 \\
\frac{\partial \theta_{c}}{\partial \beta}>0
\end{array}\right.
$$

Meanwhile, we can conclude from formula (6) that:

$$
\left\{\begin{array} { l l } 
{ \frac { \partial \theta _ { c } } { \partial k } > 0 } \\
{ \frac { \partial \theta _ { c } } { \partial \beta } > 0 }
\end{array} \quad \left\{\begin{array} { l } 
{ \frac { \partial \pi _ { u } ^ { c } } { \partial k } > 0 } \\
{ \frac { \partial \pi _ { u } ^ { c } } { \partial \beta } > 0 }
\end{array} \quad \left\{\begin{array}{l}
\frac{\partial \pi_{d i}^{c}}{\partial k}>0 \\
\frac{\partial \pi_{d j}^{c}}{\partial \beta}>0
\end{array}\right.\right.\right.
$$

Therefore, as for the R\&D effect, the profits of upstream enterprise and downstream member enterprises are all increasing functions concerning absorptive capacity $k$ and overflow level $\beta$. Since $0 \leq k \leq 1$ and $0 \leq \beta \leq 1$, the total profit in the equilibrium state is maximum when $k^{*}=1$ and $\beta^{*}=1$. At this point, various indexes of cooperative R\&D are shown as follows:

$$
\left\{\begin{array}{l}
\theta_{c}^{*}=\frac{N\left(a-c_{0}-\omega\right)}{(N+1)} \frac{1}{\gamma S-\frac{2 n}{(N+1)(N-n+2)^{2}}} \\
\pi_{u}^{c}=\frac{N\left(a-c_{0}-\omega\right)^{2}}{4(N+1)}+\frac{N^{2}\left(a-c_{0}-\omega\right)^{2}}{4(N+1)^{2}} \frac{1}{\gamma S-\frac{2 n}{(N+1)(N-n+2)^{2}}} \\
\pi_{d i}^{c}=\frac{1}{(N+1)^{2}}\left(\frac{a-c_{0}-\omega}{2}+\frac{2(N-n+1)}{N-n+2} \theta_{c}^{*}\right)^{2}-\frac{1-S}{2} \gamma \theta_{c}^{* 2} \\
\pi_{d j}^{c}=\frac{1}{(N+1)^{2}}\left(\frac{a-c_{0}-\omega}{2}-\frac{n \theta_{c}^{*}}{N-n+2}\right)^{2}
\end{array}\right.
$$

\subsection{Model Comparative Analysis of Independent R\&D and Cooperative R\&D}

The profit function and effect function of upstream enterprise and downstream enterprise under initial status, independent $\mathrm{R} \& \mathrm{D}$ and cooperative $\mathrm{R} \& \mathrm{D}$ have already been worked out above. In order to make it convenient to demonstrate, Table 2 below is used for summarization and description.

(1) The profit of the upstream enterprise obtained during cooperative $R \& D$ innovation is greater than that during independent R\&D innovation, while the profit obtained during independent $\mathrm{R} \& \mathrm{D}$ innovation is greater than that of initial status, i.e. $\pi_{u}^{c}>\pi_{u}^{s}>\pi_{u}^{0}$.

We can see from the expressions of $\pi_{u}^{s}$ and $\pi_{u}^{0}$, it is apparent that $\pi_{u}^{s}>\pi_{u}^{0}$; then prove $\pi_{u}^{c}>\pi_{u}^{s}$.

$$
\begin{aligned}
\pi_{u}^{c} & -\pi_{u}^{s}=\frac{N^{2}\left(a-c_{0}-\omega\right)^{2}}{4(N+1)} \\
& \times\left[\frac{1}{2(N+1) \gamma S-\frac{4 n}{(N-n+2)^{2}}}-\frac{1}{4(N+1) \gamma-N}\right]
\end{aligned}
$$

The formula above is apparently greater than zero, indicating that the upstream enterprise can obtain bigger benefit by adopting cooperative R\&D innovation than independent $\mathrm{R} \& \mathrm{D}$ innovation. Therefore, the upstream enterprise is more willing to conduct cooperative R\&D with downstream enterprises. As we know, number of downstream enterprises $N$, initial production cost of upstream enterprise $c_{0}$, processing cost of downstream enterprises $\omega$, coefficient of difficulty of R\&D $\gamma$ and market scale $a$ are all exogenous variables. As a result, the profit and $R \& D$ benefit function of the upstream enterprise are only influenced by the number of member enterprises $n$ and R\&D cost-sharing ratio $S$.

To make it convenient to understand, make: 
Table 2. Comparison of independent $R \& D$ and cooperative $R \& D$.

\begin{tabular}{|c|c|c|}
\hline & Independent R\&D & Cooperative R\&D \\
\hline Upstream enterprise & $\pi_{u}^{s}=\frac{N\left(a-c_{0}-\omega\right)^{2}}{4(N+1)-N / \gamma}$ & $\begin{array}{l}\pi_{u}^{c}=\frac{N\left(a-c_{0}-\omega\right)^{2}}{4(N+1)} \\
+\frac{N^{2}\left(a-c_{0}-\omega\right)^{2}}{4(N+1)^{2}} \frac{1}{\gamma S-\frac{2 n}{(N+1)(N-n+2)^{2}}}\end{array}$ \\
\hline Downstream member enterprises & $\pi_{d i}^{s}=\frac{\left(a-c_{0}-\omega+\theta_{s}^{*}\right)^{2}}{4(N+1)^{2}}$ & $\begin{array}{l}\pi_{d i}^{c}=\frac{1}{(N+1)^{2}}\left(\frac{a-c_{0}-\omega}{2}+\frac{N-n+1}{N-n+2} \theta_{c}\right)^{2} \\
\ldots \ldots .-\frac{1-S}{2} \gamma \theta_{c}^{2}\end{array}$ \\
\hline Downstream non-member enterprises & & $\pi_{d j}^{c}=\frac{1}{(N+1)^{2}}\left(\frac{a-c_{0}-\omega}{2}-\frac{n \theta_{c}}{N-n+2}\right)^{2}$ \\
\hline$R \& D$ benefit function & $\theta_{s}^{*}=\frac{N\left(a-c_{0}-\omega\right)}{2(N+1)-N}$ & $\theta_{c}^{*}=\frac{N\left(a-c_{0}-\omega\right)}{(N+1)} \frac{1}{\gamma S-\frac{2 n}{(N+1)(N-n+2)^{2}}}$ \\
\hline
\end{tabular}

$\eta=\gamma S-\frac{2 n}{(N+1)(N-n+2)^{2}}$, Then:

$\left\{\begin{array}{l}\theta_{c}=\frac{N\left(a-c_{0}-\omega\right)}{2(N+1)} \frac{1}{\eta} \\ \pi_{u}^{c}=\frac{N\left(a-c_{0}-\omega\right)^{2}}{4(N+1)}+\frac{N^{2}\left(a-c_{0}-\omega\right)^{2}}{8(N+1)^{2}} \frac{1}{\eta}\end{array}\right.$

Carry out derivation of $\eta$ against $S_{\text {and }} n$.

$$
\left\{\begin{array}{l}
\frac{\partial \eta}{\partial S}=\gamma>0 \\
\frac{\partial \eta}{\partial n}=-\frac{2}{N+1}\left[\frac{1}{(N-n+2)^{2}}+\frac{2 n}{(N-n+2)^{3}}\right]<0
\end{array}\right.
$$

Apparently, the rise of $R \& D$ cost-sharing ratio Swill lower the R\&D effect of the downstream enterprise and reduce the profit of the upstream enterprise; the R\&D effect and the profit function of the upstream enterprise will increase with the increase of number of downstream member enterprises $n$. Therefore, the upstream enterprise will expect the shared R\&D cost as small as possible and the number of enterprises joining in cooperative $R \& D$ more the better. When $n_{u}^{*}=N$, both R\&D effect and profit of the upstream enterprise reach the optimal.

(2) When $\mathrm{N}$ is big enough and $\frac{4 N+2}{9(N+1) \gamma}<S<\frac{5 N}{18 \gamma}+\frac{3 N-4}{18 \gamma(N+1)}$ is satisfied, the scale of cooperative $R \& D$ alliance expected by the downstream member enterprises is less than the size of cooperative $R \& D$ alliance expected by the upstream enterprise, i.e. $n_{d}^{*}<n_{u}^{*}$.

To prove $n_{d}^{*}<n_{u}^{*}=N$ is to prove $\pi_{d i}^{c}(n=N)-\pi_{d i}^{c}(n=N-1)<0$.

$$
\begin{aligned}
\pi_{d i}^{c}(N)-\pi_{d i}^{c}(N-1) \\
=\frac{1}{(N+1)^{2}}\left[\left(a-c_{0}-\omega\right)+\frac{1}{2} \theta_{c}(N)+\frac{2}{3} \theta_{c}(N-1)\right] \\
\quad \times\left[\frac{\theta_{c}(N)}{2}-\frac{2 \theta_{c}(N-1)}{3}\right]-\frac{(1-S) \gamma}{2} \frac{(N-1) \theta_{c}^{2}(N)-N \theta_{c}^{2}(N-1)}{N(N-1)}
\end{aligned}
$$

We can see from the R\&D benefit function, the following formula is established when $n=N$ and $n=N-1$ :

$$
\left\{\begin{array}{l}
\theta_{c}(N)=\frac{N\left(a-c_{0}-\omega\right)}{2(N+1) \gamma S-N} \\
\theta_{c}(N-1)=\frac{N\left(a-c_{0}-\omega\right)}{2(N+1) \gamma S-\frac{4}{9}(N-1)}
\end{array}\right.
$$

Substitute $\theta_{c}(N)$ and $\theta_{c}(N-1)$ into $\pi_{d i}^{c}(N)-\pi_{d i}^{c}(N-1)$ to obtain:

$$
\text { When } \frac{4 N+2}{9(N+1) \gamma}<S<\frac{5 N}{18 \gamma}+\frac{3 N-4}{18 \gamma(N+1)}, \quad \pi_{d i}^{c}(n=N)-
$$
$\pi_{d i}^{c}(n=N-1)<0$ is established.

Therefore, if the R\&D cost-sharing ratio $S$ satisfies the conditions above, unlike the upstream enterprise which expects the participation of all enterprises in cooperative R\&D, the downstream member enterprises do not expect that, for the more the downstream enterprises participating in the cooperative R\&D and the more fierce the downstream competition will be, thus resulting in the weakening of cost advantage of member enterprises. Meanwhile, we can conclude by analyzing the profit functions of downstream member enterprises and downstream non-member enterprises that the implementation of technical $R \& D$ by the upstream enterprise will result in the decline of profits of downstream nonmember enterprises. Besides, the increase of R\&D effect of upstream enterprise $\theta_{c}$ and number of downstream member 
enterprises $n$ will reduce the profits of downstream nonmember enterprises. Although the profit function of downstream member enterprise increases with the R\&D activities of the upstream enterprise, it will decline with the increase of the number of downstream member enterprises or the increase of shared R\&D cost. Therefore, the profits of downstream member enterprises are the result of comprehensive consideration of multiple factors. The cost sharing tactic established by the upstream enterprise is the key factor influencing the cooperation of upstream and downstream enterprises.

The analysis above indicates that the upstream enterprise cannot independently decide the cost-sharing ratio of cooperative $R \& D$ innovation and the scale of downstream member enterprises although it is in a monopoly position in the whole supply chain. It has to obtain the approval of the downstream member enterprises before launching cooperation. If the cooperation scheme established by the upstream enterprise is declined by the downstream enterprises, the upstream enterprise has to independently undertake this R\&D task and pay all R\&D cost [10].

(3) As for downstream member enterprises, two conditions must be fulfilled in order to participate in cooperative R\&D. Firstly, the profit during cooperative R\&D shall not be lower than the profit without cooperation. Besides, the profits of the member enterprises shall not be lower than the profits of non-member enterprises, i.e. $\pi_{d i}^{c} \geq \pi_{d i}^{s}$ and $\pi_{d i}^{c} \geq \pi_{d j}^{s}$

In the vertical cooperative $R \& D$ innovation tactics with complete upstream monopoly, the upstream and downstream enterprises are unequal in terms of cooperation position. The upstream enterprise has led the establishment of the whole R\&D cost-sharing tactic. It will establish the most favorable cost-sharing tactic when it is acceptable for the downstream member enterprises. In order to make the downstream enterprises willing to join the cooperative $R \& D$ alliance, the costsharing tactic established by the upstream enterprise shall satisfy the participation constraint $\left(\pi_{d i}^{c} \geq \pi_{d i}^{s}\right)$ and incentive compatible constraint $\left(\pi_{d i}^{c} \geq \pi_{d j}^{s}\right)$. We can see from above that the profits of downstream non-member enterprises will decline after cooperative R\&D. Therefore, the cost-sharing tactic established by the upstream enterprise is only required to make the downstream enterprises satisfy the participation constraint $\pi_{d i}^{c} \geq \pi_{d i}^{s}$, i.e.:

Convert this formula

$$
\frac{1}{(N+1)^{2}}\left(\frac{a-c_{0}-\omega}{2}+\frac{N-n+1}{N-n+2} \theta_{c}\right)^{2}-
$$

$\frac{1-S}{2} \gamma \theta_{c}^{2} \geq \frac{\left(a-c_{0}-\omega+\theta_{s}\right)^{2}}{4(N+1)^{2}}$ to obtain:

$\frac{1}{(N+1)^{2}}\left[\left(a-c_{0}-\omega+\frac{N-n+1}{N-n+2} \theta_{c}+\frac{\theta_{s}}{2}\right)\left(\frac{N-n+1}{N-n+2} \theta_{c}-\frac{\theta_{s}}{2}\right)\right] \geq \frac{1-S}{2} \gamma \theta_{c}^{2}$

Substitute it to the expressions of $\theta_{s}$ and $\theta_{c}$ to solve the cost-sharing ratio with the participation constraint satisfied:

$$
S \geq \frac{\frac{8 n^{2}(N-n+1)}{N-n+2}+\gamma N(N+1)^{2}(N-n+2)^{2}-2 N n(N-n+1)^{2}}{\gamma\left[N(N+1)^{2}(N-n+2)^{2}+4 n(N-n+1)(N-n+2)(N+1)\right]}
$$

Make:

$$
S^{*}=\frac{\frac{8 n^{2}(N-n+1)}{N-n+2}+\gamma N(N+1)^{2}(N-n+2)^{2}-2 N n(N-n+1)^{2}}{\gamma\left[N(N+1)^{2}(N-n+2)^{2}+4 n(N-n+1)(N-n+2)(N+1)\right]}
$$

As for upstream enterprise, its R\&D benefit and profit are maximized when the cost-sharing ratio is established as $S^{*}$.

(4) In the interval of $[0, N]$, a maximum value exists in the increasing function of profit function of the upstream enterprise concerning the number of downstream enterprises $n$. The maximum value exists when $n^{*}=N$; it is an increasing function of the sharing ratio determined by the upstream enterprise concerning number of downstream enterprises $n$. Therefore, a minimum value exists.

(5) This chapter has also drawn some other conclusions through analysis and deduction:

Under the cooperative R\&D status, the profits of downstream non-member enterprises monotonously decrease with the increase of number of downstream members and the expansion of total scale of downstream enterprises.

Under the cooperative $R \& D$ status, the cost-sharing ratio of the upstream enterprise is a concave function concerning the number of upstream member enterprises. It has a process which decreases first and increases later. When the number of downstream member enterprises reaches stationary point, the cost-sharing ratio of upstream enterprise reaches the minimum. When establishing cost-sharing ratio, the upstream enterprise must consider the benefits of the downstream enterprises [11]. Under an acceptable condition of the downstream member enterprise, the upstream enterprise can gradually adjust it cost-sharing ratio. Besides, the costsharing ratio of the upstream enterprise $S$ does not monotonously declines with the number of downstream member enterprises. It presents a U-shaped trend which decreases first and increases later.

Under the cooperative $R \& D$ status, both $R \& D$ effect function and profit function of the upstream enterprise are convex functions concerning the number of downstream member enterprises and reach the maximum values at $n^{*}$ simultaneously. After the participation constraint of downstream member enterprises is considered, the R\&D effect function and the profits of upstream enterprise will not monotonously increase with the increase of the number of downstream member enterprises $n$. Instead, it presents a Ushaped changing trend. When the number of downstream member enterprises increases from 0 to $n^{*}$, the R\&D effect and the profit of the downstream enterprise increases gradually; when the number of downstream member enterprises reaches $n^{*}$, the R\&D effect and the profit of the upstream enterprise reach the maximum; when the number of downstream member enterprises is greater than $n^{*}$, the R\&D ef- 
fect and the profit of the upstream enterprise will gradually decline. Besides, with the expansion of total scale of downstream enterprise, the profit function curve of the upstream enterprise will move downward as a whole, and the maximum profit at $n^{*}$ will also decrease. However, since the upstream enterprise has considered the participation constraint of downstream member enterprises when establishing costsharing tactic, the scale of downstream member enterprises determined by the upstream enterprise is not equal to $\mathrm{N}$ $\left(n^{*} \neq N\right)$.

\section{CONCLUSION}

Therefore, this paper has established a secondary supply chain structure with complete upstream monopoly. Meanwhile, in consideration of the absorptive capacity and overflow effect of the enterprises, it has internalized the costsharing ratio, $R \& D$ effect and $R \& D$ input of the upstream enterprise and discussed the influence of the cooperative R\&D tactics of the upstream enterprise on the scale of cooperation alliance, cost-sharing ratio, $R \& D$ effect and profits of upstream and downstream enterprises when the upstream enterprise conducts technical $R \& D$. The researches have indicated that the profit obtained by the upstream enterprise during cooperative $R \& D$ is higher than that obtained during independent $R \& D$, and the profits of the downstream member enterprises obtained during cooperative $R \& D$ are greater than the profits before cooperation in the vertical cooperative R\&D model with complete upstream monopoly. It means cooperative $R \& D$ is not a zero-sum game but a "win-win" situation. With the increase of the enterprises' absorptive capacity and overflow level, the R\&D effect of the enterprises and the profits of the upstream and downstream enterprises will increase and reach the optimum when $k^{*}=1$ and $\beta^{*}=1$. Meanwhile, even if the upstream enterprise owns the monopoly position and has a certain leading role in the market, the upstream monopoly enterprise cannot force the downstream companies to join the cooperative $R \& D$ alliance, and undertake research and development costs too much. To maximize profits, the upstream companies can only travel companies in the following bound for the stan- dard to determine the number of member companies and the downstream cost-sharing ratio.

\section{CONFLICT OF INTEREST}

The authors confirm that this article content has no conflict of interest.

\section{ACKNOWLEDGEMENTS}

Declared none.

\section{REFERENCES}

[1] S. Banerjee, and P. Lin, "Downstream R\&D, raising rivals' costs, and input price contracts," International Journal of Industrial Organization, vol. 21, pp. 79-96, 2003.

[2] S. Banerjeea, and P. Lin, "Vertical research joint ventures," International Journal of Industrial Organization, vol. 19, pp. 285-302, 2001.

[3] A. Ishii, "Cooperative R\&D between vertically related firms with overflows," International Journal of Industrial Organization, vol. 22, pp. 1213-1235, 2004.

[4] G. Aust, and U. do. Buscher, "Vertical cooperative advertising and pricing decisions in a manufacturer-retailer supply chain: A gametheoretic approach," European Journal of Operational Research, vol. 223, pp. 473-482, 2012.

[5] M. Peitz, and D. Shin, "Innovation and waste in supply chain management," Journal of Economic Behavior \& Organization, vol. 86, pp. 191-199, 2013.

[6] T. Iida, "Coordination of cooperative cost-reduction efforts in a supply chain partnership," European Journal of Operational Research, vol. 222, pp. 180-190, 2012.

[7] M. M. S. Esfahani, M. Biazaran, and M. Gharakhani, "A game theoretic approach to coordinate pricing and vertical co-op advertising in manufacturer-retailer supply chains," European Journal of Operational Research, vol. 211, pp. 263-273, 2011.

[8] M. Nagarajan, and G. Sošić, "Game-theoretic analysis of cooperation among supply chain agents: review and extensions," European Journal of Operational Research, vol. 187, pp. 719-745, 2008.

[9] B. K. Bahinipati, and S. G. Deshmukh, "Vertical collaboration in the semiconductor industry: A decision framework for supply chain relationships," Computers \& Industrial Engineering, vol. 62, pp. 504-526, 2012.

[10] M. Hülsmann, J. Grapp, and Y. Li, "Strategic adaptively in global supply chains-Competitive advantage by autonomous cooperation," International Journal of Production Economics, vol. 114, pp. 1426, 2008.

[11] M. Leng, and M. Parlar, "Game-theoretic analyses of decentralized assembly supply chains: Non-cooperative equilibria $v s$. coordination with cost-sharing contracts," European Journal of Operational Research, vol. 204, pp. 96-104, 2010. 